\title{
Syntactical and Punctuation Errors: An Analysis of Technical Writing of University Students Science College, Taif University, KSA
}

\author{
Abdulamir Alamin \\ Taif University, KSA, Canada \\ E-mail: aalamin1@hotmail.com \\ Sawsan Ahmed \\ Taif University, KSA, Canada
}

Received: August 1, 2011

Accepted: February 24, 2012

Published: May 1, 2012

doi:10.5539/elt.v5n5p2

URL: http://dx.doi.org/10.5539/elt.v5n5p2

\begin{abstract}
Analyzing errors committed by second language learners during their first year of study at the University of Taif, can offer insights and knowledge of the learners' difficulties in acquiring technical English communication. With reference to the errors analyzed, the researcher found that the learners' failure to understand basic English grammar could be ascribed to intralingual interference which is associated with the developmental sequence of learning English for technical communication in the form of speaking, listening, reading and writing, rather than to interference of the mother tongue. The results will be of benefit for material development, especially in the provision of materials in the Language Learning Centre.
\end{abstract}

Keywords: English for Special Purposes, English as Second Language, English as a Foreign Language, Interlanguage, Target language

\section{Introduction}

During the initial stages of learning a foreign language (FL) or second language (SL), learners have no knowledge or command of the FL/SL. As the learners gradually move towards their FL/SL goals they progress through what Selinker calls their Interlanguage (IL) (Selinker 1972, 1992). Interlanguage occurs during the stage in which the learner has not yet achieved proficiency and emphasizes what they know and do not know about the target language (TL), (Corder, 1975).

Interference from the mother tongue is believed to be the major source of learning problems with regard to the target language. The notion of interference was first used by Urid Weinreich (1953) to the negative influence of one language on another in a bilingual situation. Learning problems, therefore, may vary according to the type and the degree of interference from the native language. Lee (1968) claimed that the interference of the mother tongue takes different shapes and they are chiefly responsible for the learning difficulties of the target language. On the other hand, Wilkins (1973) believed that if the structures of the two languages are the same, no difficulty is anticipated and teaching is not necessary, simple exposure to the language will be enough. The theory of interference gave rise to Contrastive Analysis, which became the primary model in the 1960s. This method involved identifying comparable features of the mother tongue, and then comparing the forms and meanings between the two languages in order to find the similarities and differences. Analysis of this data was used to shed light on interference and errors made by the learners. Research showed that up to 30 percent of the errors that learners would make are a result of wrongly transferring language systems to the target language. (James, 1971)

Contrastive Analysis helped to shed light on language differences and enabled teachers as well as textbook writers to predict the learning problems that learners of a given foreign language are expected to face. The list of learning problems should not be taken to represent more than a list of potential problems that are likely to face the majority of learners in the majority of cases. (Lado, 1957)

Contrastive Analysis (CA) began to lose its prominence due to its association with an outdated model of language description of the Structuralism and the learning theory of the Behaviorism of the Habit formation. James predicted that the learning difficulties formulated on the basis of CA were not entirely accurate since either teachers had known about the errors already or the errors were not dealt with during the learning process... Errors on this account 
were predicted to occur entirely at points of separation of L1 from L2.

CA would be replaced by Error Analysis, which compared the two languages in order to identify differences without blaming the mother tongue. In other words, errors would be fully described in terms of the target language, without the need to refer to the learners' mother tongue.

In the late 1980s researchers took an interest in learners' errors as they found that the learners' first language is not the only linguistic factor affecting the acquisition of the English language as a second or foreign language. The learners' failure to grasp the English language comprehensively could be ascribed to intralingual interference, which was associated with the general learning strategies. (Oxford, 2001). Many problems were discovered to be the causes for learners' errors. These include: overgeneralization, ignorance of the rules of restriction, incomplete application of errors and false concepts hypothesized. (Corder, 1971)

Nevertheless, it has been proven beyond doubt that the effects of the mother tongue on the target language cannot be denied. Wardhaugh (1970) suggested that contrastive analysis had no predictive power and all L2 errors could be predicted. This has led to some like Kellerman and Sharwood (1986) to talk of 'cross-linguistic influence, and Selinker (1983) of language transfer, and James (1990) preferred to use "transfer analysis. However, no scholars have doubted that the mother tongue has at least some level of influence on the process of learning the target language. The learners' prior linguistic knowledge, of one language or many languages, should have its effect on learning the target language.

James (1990) explored two potential causes of errors:

1. Interlingual Interference. This is caused from the interference of the mother-tongue. Learners have a tendency to copy every word of the learners' first language into the target language. In contrastive analysis, it is believed that the type of errors made by the learners of the target language can be predicted and their causes can be determined. In order to reduce if not eliminate these errors. Richards (1974) argues that between 3-25 per cent of all errors are errors of mother tongue influence and 75 per cent of errors are 'non-contrastive' errors.

2. Intralingual Interference. These types of errors are caused by the target language (TL) itself. Apart from recourse to L1 transfer, either they can set about learning the needed item, engaging their learning strategies, or they can try to fill the gap by resorting to communication strategies. Learning strategies are used for code breaking while communication strategies are encoding and decoding strategies. Both types of strategy can be the source of error.

Errors caused by learning strategies include:

1. Analogy which also seemed a source of errors in the misuse of verbs, prepositions, and pronouns. Students attempt to follow the same forms in different situations. These are some of the examples:

"He showed me the equipment" becomes "He explained me the equipment";

"ask him to do it" becomes "Make him to do it". (Richards, 1980)

2. Grammatical errors: These happen in the shape of incomplete grammatical sentences. This happens when the learners try to simplify the sentence rather than get the whole structure correct. It is obvious in the use of direct and indirect questions. For instance: "I have no idea where is she?" The learners have applied only two components of the interrogative formation rule: they have selected and fronted a who-element (rule components 1 and 2), but failed to invert the subject and verb. Other examples include learners failing to follow the restricted rules of some syntax. Examples of this include failing to follow the rules of verbs followed by infinitives or gerunds. So we often find students saying "I enjoy to read" rather than "I enjoy reading."

3. Redundancy: This error occurs by carrying considerable unnecessary vocabulary. This is shown throughout the system in the form of unnecessary addition of words and indefinite articles.

4. Overcorrection: learners tend to be over cautious to avoid mistakes. Wrong sentences would be the result. An example of this is:" I have son five year(s) old."

5. Overgeneralization: This error is caused by the misuse of words or grammatical rules.

\section{English for Special Purposes (ESP)}

English for Specific Purposes (ESP) is now well known and established as a significant and an important part of English Language Teaching. English language teaching has been revolutionized during the past years with the explosion in business and commerce. Many researchers have offered a number of books and articles bringing new ideas and syllabus approaches from different theoretical angles. Since the late 1950's ESP has changed in many different ways. English for Business Purposes has become an increasingly important industry, even dominant, area of ESP. Teachers and educators realized that technical reading and writing are important to raise students' 
performance in oral English in specialized fields. First, they tried to establish the syllabus and the curriculum according to the grammar and vocabulary of the language used in certain areas. A Course in Basic Scientific English compiled by Ewer and Latorre (1969) is a good example of this trend. Later on in the 1980s a new approach focused on needs analysis of the learners. Therefore the ESP course design should proceed by identifying the target situation first, and then carrying out a rigorous analysis of the linguistic features of that situation. (Trimble, 1985).

The work of discourse analysis and the results of computer-based analysis on the other hand provided a fuller understanding of how specific texts, both written and spoken, work. ESP covers a wide range of both theoretical and methodological topics. ESP has been influenced by new ideas in the areas of management training, human resource development, sociology and intercultural training.

Robinson (1980) emphasized that any ESP course or program is not the same as an ordinary English language course. He went on further to explain that they are different at least in the following areas:

1. An ESP course is orientated towards the needs of a specific group of people specialized in a certain field of scientific knowledge.

2. An ESP course is geared towards the teaching of English as a foreign language or a second language.

3. The program is clear and sound in its educational objectives taking into consideration the learners' age, level of schooling and training, interest and future career.

4. The vocabulary should be in technical terms from the area of specialty rather than an ordinary one. Hence, 'sodium chloride' rather than 'salt'. Technical vocabulary of Greek or Latin origin might be strange or difficult at the beginning to the students learning technical English but they have to get familiar with them. Students of Science and Engineering might face difficulties in framing the plurality of technical words since they know only one way of formation of plurality in secondary schools; the adding of 's, es, iz' to the words depending on the nature of the final sound with some exceptions.

5. The form of English language of the ESP is different from that of an ordinary English language program. This involves modes of expression, style and register of the tests used. For example, the imperative and the passive forms are frequently used. Thus, instead of "I turn a gas- jar upside down", we say "Turn a gas-jar upside down", or "A gas-jar is turned upside down".

6. Simple present tense is used in sentences describing experiments and facts.

7. Speaking and written exercises along with listening practice and reading materials are of technical nature and geared towards the vocabulary needs of the learners.

8. Tests and evaluation should be designed accordingly to measure students' learning objectives.

\section{Research Data}

This paper analyses the errors students have made in their homework assignments and in their writing compositions. The focus will be on the possible ways in which errors could be avoided in their gradual process of learning English for technical communication.

The corpus of this study was collected during the academic year of 2009-2010. The subjects of this analysis were male students in their first year of University, studying general science at the College of Science at Taif University, Kingdom of Saudi Arabia. The data was collected from the quizzes, homework and final examinations of one hundred students. All of the students sampled were required to have studied English as a foreign language for five to ten years in Secondary school prior to admissions into the University of Taif. English is typically taught from the Fifth Grade of Elementary School through secondary school. The majority of the subjects attended government schools (70\%) with a smaller number having attended private schools $(30 \%)$.

\section{Results and Discussion}

It is interesting to note that interference causing a large portion of errors may be both interlingual and intralingual in nature. Students' errors are classified into syntactical and punctuation errors:

The Syntactical errors are in the following:

1. Omission of Indefinite Articles (a, an).

2. Choosing the technical verbs.

3. Adjectives and adverbs.

4. Using the Simple Present and Present Continuous tenses. 
5. Plurality.

6. The possessive genitive.

7. Question forms.

8. Passive and active voice.

9. Compound nouns.

The punctuation errors were Capitalization the use of colon, semicolon, apostrophe, question mark, full stop, and comma.

\section{The Syntactical Errors}

Under each of the following headings, incorrect constructions are listed as they occurred in the students' collected papers:

1. Omission of Indefinite Articles (a, an) in sentences. Examples are:

Taif is beautiful city [a beautiful city]

I read newspaper everyday [a newspaper]

Arabic is international [an international] language.

I saw car [a car] accident near the university.

The differences between the grammatical structures of Arabic and English could cause the learners to delete the indefinite articles in the above examples.

In other examples, students used the indefinite articles with singular noun as part of the noun. An example:

"Taif University has alrage [a large] population of students". This is not a misspelling but it is believed that the indefinite article is part of the noun.

Students showed confusion in the choosing the right article, definite and indefinite articles. They substitute one for another which could be the ignorance of full knowledge of the rules of using them. Examples:

Speaking English makes the student [a student] feel good.

English is a best [the best] language for work.

The student [a student] needs English at the university.

Other errors noticed in using the indefinite article with plural nouns. An example of that:

Arabic is spoken by alarge [a large ] number of a people[ people]

A confusion [confusion] is in the class.

1. The correct technical Verbs: students have shown that difficulties in choosing the correct vocabulary even with the use of a dictionary. This could be the cause of Interlanguage interference. They failed to comprehend the core vocabulary to be used in technical and scientific English communication. Here are a few examples of these verbs wrongly used by the students in their compositions:

Students set, or fire [ignite] the oil lamp.

push in' for insert.

make up' for equalize.

'turn upside down' for invert.

small bit' for small pieces.

Fire [light] candle [the candle].

In many cases, students failed to observe the rules of using simple present tense in scientific and technical English in their writing assignments, in spite of being reminded several times. Translation from the mother tongue is another possible cause of these mistakes.

1. Adjectives and adverbs: learners of English as a second language encounter confusion in the use of adjectives and adverbs. This could be attributed to a poor strategy for learning these words. The interference of these learning strategies produces a hybrid learning structure. Examples of such sentences are:

Catch [hold] light [lighted] candle 
Ali is good [better] than others worker in the class.

The rocket was discovered in new [recent] years

Stream was perhaps more importantly [important] than invention.

2. Errors in using the tenses: Learners forget how to use Simple Present tense to articulate their statements. They used 'will' to indicate future, 'be' in passive, or other auxiliary verbs like 'can' to refer to the simple Present tense. They made up combinations of auxiliary verbs. Examples of such errors are:

He is illustrates the diagrams

the machine can works..

Oxgen and hydrogen are occur..

the liquid in those bottles is come.

it will turns..

..as it flys

this candle is leved...

...is puten

Errors may be intralingual and interlingual in nature, so we came across forms, like,' admitted, carried, exploied

3. Misuse of Plurality: it is possible that the errors committed by the learners are the results of overgeneralization of countable and uncountable nouns. So we see words such as,' two breads, steels, sugars, airs, scissors'. These are typical mistakes found in the students' sampled examination papers:

She has a very important works to do.

We have many important works to finish today.

On the basis of these datas...

4. Misuse of Possessive Genitive: Students failed sometimes to use the possessive genitive correctly. This is because it is not common to use possession in science and engineering. (Wales, 1973). Thus, learners run into sentences like:

The moon's surface

The car's maximum speed.

5. Question Forms. Students make mistakes with 'who'. Students chose 'what' instead of 'who' when they were asked to change these sentences into questions:

The manager was complaining about the quality of the products.

What were complaining about quality of the products'[?]

Students chose 'what' for 'whom' in sentences like:

The engineer is discussing the problem with the technician.

what the engineer is discussing the problems with?

6. Errors in using the Passive and Active Voice: Students seemed unable to differentiate between the passive and active. Wrong use of the past participle or unaware of the grammatical combination of the verb in the passive voice so we see sentences like: "the gas will be appear..," "then the gas-jar taken off.." In other instances, they used the Active instead of the Passive:"Madam Curie was discovered radium," "some trees uprooted."

It was obvious that their lack of knowledge of the Passive was the cause of these errors.

7. Errors in using compound nouns: Students were taught how to use compound nouns as strategy learning in writing scientific English, but they failed to use it properly. Such errors can be ascribed to the interference and intralingual interference which could have occurred as a result of the learners' ignorance of the rules governing the use of the compound words. They wrote : "shoe factory, battery car, glass bottle"

\section{The Punctuation Errors}

Eckersley (1979) reads the term 'punctuation', as ..." simply a device or making it easy to read and understand written or printed matter". 
The data obtained from the students, their examination and homework assignments, has shown that Capitalization, the use of comma and semicolon were among others are most common punctuation errors.

Experienced teachers of English as a second language have noticed punctuation to be extremely difficult and confusing for many ESL/EFL students. They do not use commas in combining simple or compound sentences to make new sentences. An example of that is:

\section{Students love Science [, and] they plan to study more}

They usually do not combine the two simple sentences by using a semicolon. An example of that:

\section{Students like Science [;] they plan to major in that disciplinary area.}

It is not unusual to see students write compound sentences using a comma without a coordinating conjunction. They use an adverb instead of conjunction. An example:

Students love Science, therefore, they want to major in this area.

Another common punctuation error noticed in the students' papers is the ability to write sentence after sentence without a period at the end of one sentence, or a capital letter at the beginning of the next. Sentences just run together. An example:

" $i$ do not forget the invitation that i sent it to you before several weeks as you said that you are very busy now you do not have any excuse to reject my invitation so however $i$ hope you choose the time that you want to get the dinner together and sent the date to me. thank you very much"

"He likes English and he wants to continue study"

Students were asked to rewrite some passages and sentences in the correct forms of punctuation. Their errors can be categorized into the following:

1. Starting new sentences with lower case letters.

2. Not using capital letters for proper nouns.

3. Using the colon incorrectly.

4. Using the semicolon incorrectly at the beginning of the passages and after the words.

5. The exclamation mark hardly used.

6. Forgetting to use full stops at the end of a sentence.

7. Not using enough space between words.

8. Hardly using question marks.

9. Hardly using hyphens.

\section{Conclusion}

Through the analysis of the data, the researcher found that the learners' failure to understand basic English grammar could be ascribed to intralingual interference, which is associated with developmental sequence of learning English for technical communication. Communication may be in the form of speaking, listening, reading and writing, rather than to interference of the mother tongue. It was noted that intralingual interference seems to be as important as interlingual interference in the learning of the English for technical communication.

An ESP course is not a general English course, but rather a course with materials specially selected for a certain group of learners with a special learning strategy targeting the learners' needs. A plan of action is necessary to ensure that programs manifest adequate objectives in operational and behavioral terms to suit the needs of a specific group of learners. The objectives ought to be sound in terms of the learners' previous knowledge of English, level of training and the influence of the mother tongue and the differences with the English language. The current English course at the College of Science needs to be reviewed and take into consideration the above criteria in choosing the right teaching materials. At present it is not an ESP course but rather a compilation of handouts. Further studies are needed to research the most appropriate teaching syllabus for the Science students.

The components of the present teaching materials did not show any definite pattern of integration both horizontally and vertically. There should be an adequate amount of repetition and review work. Cognitive strategies ought to be applied to involve practice and repetition as well as creation of grammatical structure for input and output. This means raising the learners' knowledge of the grammar and structure of the English language. Learners needed to constantly check the grammar and vocabulary they learned. It means also to raise the learners' consciousness of intralingual differences associated with syntactical and punctuation rules. They need to be encouraged to use the dictionary both in and out of the classroom. 
The above mentioned errors should be brought to both the learners' and teachers' attention. Teachers should exert extra effort in teaching these aspects. These should be done simultaneously with speaking and reading exercises. Learners should be familiarized with singular/plural subjects, auxiliary verbs in combination with other verbs, question forms, present simple and continuous tenses, and technical writing techniques.

There should be more adequate coordination and reinforcement in reading, listening, writing, and oral practice. Learners should be supplied with more resources for learning technical vocabulary. These are not the only errors but just a sample of what teachers should bear in mind when planning for the next technical course for the students of Science College in their first year of the B.Sc. program.

\section{References}

Chomsky, N. (1957). Syntactic Structures. The Hague: Mouton.

Chomsky, N. (1986). Knowledge of Language: Its Nature, Origin and Use. New York, Praeger.

Eckersley, E. C. (1979). A Comprehensive English Grammar for Foreign Students. London: Longman.

Ellis, Rod. (1990). Instructed Second Language Acquisition: Learning in the Classroom. Blackwell. USA.

Fries, C. C. (1946). Teaching and Learning English as a Foreign Language. Ann Arbor: University of Michigan Press.

Grass, S., \& Selinker, L. (Eds). (1983). Language Transfer in Language Learning. Rowlery, Mass., Newbury.

James, C. (1974). Linguistics measures for error gravity. AVLA Journal, 12, 3-9.

James, C. (1990). Applied Linguistics, 11, 220-223. Oxford: Oxford Journal.

Kecskes, I., \& Papp, T. (2000). Foreign and Mother Tongue. LEA. London.

Kellerman, E., \& Sharwood-Smith, M. (Eds). (1986). Crosslinguistic Influence on Second Language Acquisition. Oxford, Pergamon.

Lado, R. (1957). Linguistics Across Cultures. Ann Arbor: University of Michigan Press.

Lee, W. R. (1968). Thoughts on Contrastive Linguistics. 19th Annual Round Table. Contrastive Linguistics and its Pedagogical Implications. Washington: Georgetown University Press.

Richards, J. C. (1980). Error Analysis. Perspective on Second Language Acquisition. London: Longman.

Robinson, P. (1980). ESP (English for Special Purposes). Oxford: Pergamon Press.

Skutnabb-Kangas, T., \& Phillipson, R. ( 1989). Mother Tongue: The theoretical and sociopolitical construction of a concept. In U. Ammon (Ed), Status and function of languages and language variety. New York: DeGruyter.

Trimble, L. (1985). A Discourse Approach. Cambridge: University Press.

Wales, S. (1975). Writing Scientific English. England: Nelson.

Wardhaugh, R. (1970). The Contrastive Analysis hypothesis. TESOL Quarterly, 4, 123-30. http://dx.doi.org/10.2307/ 3586182

Wardhaugh, R. (1970). Introduction to Linguistics. McGraw-Hill Companies.

Wardhaugh, R. (1971). Teaching English to speakers of other languages: The State of Art. In Lugton and Heincle.

Weinreich, U. (1953). Languages in Contrast. New York. Linguistic Circle of New York. New York.

Wilkins, D. A. (1973). Linguistics in Language Teaching. London: Edward Arnold.

\section{Authors}

Abdulamir Alamin is an Associate Professor of Applied Linguistics at the College of Arts of Taif University in KSA. He is a Master of Education and Ph.D. holder of University of Wales and a certified Secondary School and ESL teacher from Ontario, Canada. He has been teaching ESL and applied linguistics for the last seventeen years. His interest is ESL and language acquisition.

Sawsan Ahmed is an Associate Professor at Taif University. She has done her post graduate degrees at the University of Wales, UK. She is a member of the Ontario College of Teachers and TESL Ontario. She has worked in a number of universities and colleges like the University of Garyunis in Benghazi, Libya, The University of Michigan and Henry Ford Community College in the United States, Nizwa University in the Sultanate of Oman, and currently at Taif University in the Kingdom of Saudi Arabia. Her major interest is improving the teaching /process in all its variables and factors. 